\title{
DEBATE
}

\section{Response to Ronald M Perkin and David B Resnik: The agony of trying to match sanctity of life and patient-centred medical care}

\section{H Kuhse}

Correspondence to: Dr H Kuhse, Centre for Human Bioethics, Monash University, Clayton, Victoria 3168, Australia; Helga.Kuhse@

arts.monash.edu.au

Revised version received 8 April 2002

Accepted for publication

8 April 2002
Perkin and Resnik advocate the use of muscle relaxants to prevent the "agony of agonal respiration" arguing that this is compatible with the principle of double effect. The proposed regime will kill patients as certainly as smothering them would. This may lead some people to reject the argument as an abuse of the principle of double effect. I take a different view. In the absence of an adequate theory of intention, the principle of double effect cannot distinguish between the intentional and merely foreseen termination of life, and cannot rule out end-of-life decisions that are often regarded as impermissible.

What Perkin and Resnik are in effect saying is that there are times when physicians have good reasons to end a patient's life-deliberately and intentionally-for the patient's (and the family's) sake. Why not say so-instead of going through the agony of trying to match sanctity of life and patient-centred medical care?
A ccording to traditional morality and the law, human life has sanctity and it is always impermissible or wrong to kill an innocent human being. Defenders of this view have frequently gone to extraordinary length to find ways in which they might avoid the sometimes starkly counterintuitive consequences to which the prohibition of killing would seem to commit them. Arguments about permissible and impermissible end-of-life decisions in the practice of medicine are a case in point.

Widely accepted reasoning from best interests and respect for patient autonomy suggests that physicians should sometimes lend death a helping hand. But such patientcentred approaches are in conflict with the traditional sanctity of life view. This is often denied. The prohibition of killing, it is said, does not entail that physicians must always preserve life. While physicians must not intentionally cut short a patient's life, or engage in acts of euthanasia, they may sometimes-under the principle of double effect-act in ways that will foreseeably but non-intentionally cause death. This has led to a situation where once highly contentious practices, such as the removal of patients from ventilators, the foregoing of nutrition and hydration, and terminal sedation have found increasing medical and legal acceptance.

Ronald Perkin and David Resnik take matters one step further. ${ }^{1}$ They argue that the principle of double effect allows not only recourse to terminal or total sedation, but also the employment of neuromuscular blocking agents (or muscle relaxants), to prevent "the agony of agonal respiration". While death is a foreseen consequence of what the physician does, death is not intended, either as an end or as a means. Rather, to prevent "the agony of agonal respiration", physicians can legitimately administer muscle relaxants and cause the patient's death without violating either traditional morality, or their consciences.

The principle of double effect and its central distinctionthat between merely foreseen and directly intended consequences-is necessitated by absolute prohibitions, such as the prohibition of killing. As Perkin and Resnik correctly note, without the principle of double effect, even widely accepted non-treatment decisions would be questionable and the principle of double effect would collapse. ${ }^{2}$ I think the time has come to help it on its way. As well as being highly questionable on philosophical and ethical grounds, the principle stands in the way of good patient care. It encourages hypocrisy and self deception, and has produced many a tortured argument where writers struggle to show that what looks like a bad or prohibited means to a good end is "really" only a side effect of what the physician does. ${ }^{3}$

When I first read Perkin and Resnik's paper, I was reminded of an argument by Leonard Geddes, who appealed to the principle of double effect to show that contrary to traditional Catholic teaching, a surgeon who crushes the skull of a fetus in order to remove it from a pregnant woman's body, to save her life, is not intentionally killing the unborn child:

The surgeon must remove the child from the mother's womb; the dimensions are such that if the surgeon attempts to remove it without changing these dimensions the mother will surely die. He therefore alters these dimensions in certain ways. A necessary but quite unneeded and unwanted consequence of this procedure is that the child dies. Clearly, the death of the child does not enter into consideration as a means to anything. So, in the relevant sense, the killing of the child was not intended by the surgeon, either as an end in itself or as a means to an end. Hence, it is a mistake to think that the principle concerning the killing of the innocent applies to [this] sort of killing. ${ }^{4}$

Most people will probably regard Geddes's argument as an ingenious exercise in sophistry-most likely because they think there is something wrong in describing "the means" necessary for saving the woman's life (crushing a skull) in terms of changing the dimensions of a fetus, rather than in terms of killing the fetus so that its mother may live.

Perkin and Resnik's argument for the palliative use of muscle relaxants is constructed in a similar way. Although the authors coyly refrain from mentioning it, muscle relaxants administered to patients in the grip of agonal gasping, will kill the patients as certainly as smothering them would. Agonal respiration can, as my colleagues in anaesthetics and palliative care have told me, be stopped only by stopping breathing. This means that the "proper dose" the authors refer to is a lethal 
dose. ${ }^{5}$ Following Geddes, the argument for the use of muscle relaxants may be put as follows:

In order to prevent gasping patients from dying in distress, the physician must administer muscle relaxants to stop agonal respiration. Analgesics and sedatives will not always stop gasping. A necessary but quite unneeded and unwanted consequence of administering muscle relaxants in the proper dose is that the patient dies. Clearly, the death of the patient does not enter into consideration as a means to anything. So, in the relevant sense, the killing of the patient was not intended by the physician, either as an end in itself or as a means to an end. Hence, it is a mistake to think that the principle concerning the killing of the innocent applies to [this] sort of killing.

The problem with these kinds of argument is not always, as might be supposed, that they constitute an abuse of the principle of double effect. Rather, they are often quite compatible with it. The problem lies in the principle of double effect itself. Actions can be described in many different ways, and unless limits can be set to their description and redescription, there is often no clear way of distinguishing between means and ends, between killing and letting die, and between palliative care and euthanasia.

In the absence of a theory of intention, the principle of double effect cannot set these limits. Applied in the context of the sanctity of life, it is meant to distinguish between cases of intentional and non-intentional killing. But "killing" is not a basic action; it can be described in a near infinite number of ways. I may describe my shooting of X as "moving my finger", "pulling the trigger", "firing a bullet", "making a loud noise", "causing X's death", "widowing X's husband", and so on. Similarly in medical practice: a physician may-for example, describe the withdrawal of a ventilator from a patient with respiratory failure as: "decreasing oxygen levels", "flicking a switch", "extubating a patient", "allowing a patient to die", "removing burdensome treatment", or "killing a patient".

Because it remains unclear how morally controversial actions that cause death are to be described, there is the potential for rigging the description of what is done in such a way as to predetermine whether a death is aimed at as an end or as a means, and when it is a mere side effect of what the agent does. A closer look at the principle of double effect, as stated by Perkin and Resnik, will illustrate the point. ${ }^{6}$ According to their definition, "double effect specifies that an action with two possible effects, one good (intended) and one bad (harmful), is morally permitted provided that:

1. The goal of the action (or intended effect) is itself good.

2. The intended effect is not achieved by means of the harmful effect.

3. The harmful effect is not intended, only permitted.

4. There is no other way of producing the good (intended) effect.

5. There is a proportionately good reason for allowing the harmful effect."

Provided the goal of the action is good, standard interpretations of conditions 2 and 3 rule out some actions as impermissible on the basis that they are means, rather than side effects, of what is done. But, if the goal of the action is itself good (condition 1), there is no other way of producing the good effect (condition 4), and there is a proportionate good reason for allowing the harmful effect (condition 5), what possible moral relevance could the distinction between means and side effects possibly have?

There are good patient-centred reasons why physicians should sometimes withhold life-sustaining treatment and/or administer a variety of drugs to seriously ill or dying patients, to ensure that these patient experience a good death. Surely, the answer to the question of whether, and how, they should ensure a good death, cannot just hinge on whether the patient's death is (described as) a means to, or a side effect of, what they do. Rather, a morally defensible answer must depend on whether the action is justified, in light of all the foreseen and foreseeable consequences.

Perkin and Resnik attempt to show that the principle of double effect allows the administration of muscle relaxants to patients with respiratory failure who have been removed from ventilators, and who are exhibiting patterns of prolonged agonal respiration. Is their argument successful? Perhaps. It would certainly, in my view, sometimes be morally justifiable to act in this way. Whether the action infringes the intentionality conditions of the principle of double effect is a different matter. For all the reasons outlined above, and for some others, there will be claims and counterclaims. As even the briefest look at the voluminous literature on the application of the principle of double effect to abortion and various medical end-of-life decisions demonstrates, the debate may continue for a long time-even beyond the time when caring doctors have long accepted the use of muscle relaxants in end-of-life care.

Rather than contribute myself to these tortured debates, I want to focus on a different matter. As explained by Perkin and Resnik, the central reason for the administration of muscle relaxants to gasping patients is that we have an inadequate understanding of "human sensation, awareness, and nociception". Some patients have reported feeling considerable pain, even under general anaesthesia. This means that patients who display patterns of agonal respiration, may-even when analgesics and sedatives have been provided-experience considerable pain and suffering. Given this uncertainty, "the morally most defensible position is to err on the side of relieving possible pain and suffering" ${ }^{7}$

But now notice this: there is, as far as I can see, no reason to limit the administration of muscle relaxants to patients who are gasping. If there is uncertainty about whether nonconscious patients who are dying from respiratory failure experience pain and suffering, then the same argument must, surely, also apply to seemingly unconscious patients who are not, or not yet, displaying patterns of agonal respiration. While physiological signs of distress may point to the presence of subjective distress, there can also be subjective distress without such signs. For example, patients who are experiencing pain under general anaesthesia do not, I understand, display any outward signs of distress-and yet there may be considerable pain. If this is correct, then muscle relaxants should be administered to patients when they are removed from ventilators and are allowed to die by way of suffocation, irrespective of whether there are any outward signs of distress.

More than that: if terminally ill patients are reporting intractable pain and suffering, it is becoming increasingly common to provide terminal sedation. But, again, these patients may experience considerable pain and suffering, whilst they are being allowed to die. The same reasoning that leads Perkin and Resnik to argue for the administration of muscle relaxants to gasping patients will also support the administration of these agents to patients who have been terminally sedated.

If dying, suffocating patients are gasping, this gives caring physicians an opportunity to massage the description of their action in such a way that it might become permissible under the principle of double effect. As Perkin and Resnik put it: “... gasps cannot restore or maintain life, they serve no useful purpose; however, they may cause suffering for the patient even in the presence of adequate sedation".

Yes, the patient may be suffering, is inevitably dying, and there is no point in allowing the process to continue. But it is, 
of course not the gasps that cause the suffering the patient may be experiencing-the patient is suffering because she or he is still alive and continued gasping will prolong the ordeal. What Perkin and Resnik are in effect saying is that in a situation such as this, there are good reasons why physicians should end the patient's life-deliberately and intentionally, for the patient's (and the family's) sake. Why not say so-instead of going through the agony of trying to match sanctity of life and patient-centred medical care?

\section{REFERENCES}

1 Perkin RM, Resnik DB. The agony of agonal respiration: is the last gasp necessary? Journal of Medical Ethics 2002:28:164-9.

2 See reference 1.

3 Kuhse $\mathrm{H}$. The sanctity-of-life doctrine in medicine-a critique. Oxford: Oxford University Press, 1987.

4 Geddes L. On the intrinsic wrongness of killing innocent people. Analysis 1973;34:16-19.

5 See reference 1.

6 See reference 1

7 See reference 1 . 